\title{
Short-term effect of supplemental yeast extract without or with feed enzymes on growth performance, immune status and gut structure of weaned pigs challenged with Escherichia coli lipopolysaccharide
}

\author{
Samuel M. Waititu', Fugui Yin', Rob Patterson², Juan C. Rodriguez-Lecompte ${ }^{3}$ and Charles M. Nyachoti ${ }^{* *}$
}

\begin{abstract}
Background: This study investigated the response of piglets receiving a yeast extract without or with a multi-enzyme mixture compared with an antimicrobial growth promoter (AGP) on performance, immune status and gut structure after an E. coli lipopolysaccharide (LPS) challenge. Thirty-six pigs were allotted to six treatments including: a non-challenged control (NCC); LPS-challenged control (CC); CC + AGP; CC + yeast extract; CC + enzymes; and $\mathrm{CC}+$ enzymes + yeast extract. On d 7, pigs were bled and thereafter injected with LPS or sterile saline. Blood samples were collected at 6, 48, and $96 \mathrm{~h}$ post-challenge. After $96 \mathrm{~h}$ post-challenge, pigs were euthanized to obtain duodenal, jejunal and ileal samples.

Results: Overall (d 1 to 11$)$, compared with CC pigs, AGP attenuated the LPS-induced reduction in ADG $(P=0.004)$, ADFI $(P=0.03)$ and gain/feed ratio $(P=0.01)$. At $6 \mathrm{~h}$ post-challenge, AGP pigs had lower plasma urea $N(P U N ; P=0.02)$ and serum TNF- a concentration $(P=0.07)$, and higher platelet count $(P=0.04)$ and serum IL-10 concentration $(P=0$. 02) than CC pigs. At $48 \mathrm{~h}$ post-challenge, AGP pigs had lower PUN $(P=0.02)$ than CC pigs, whereas enzymes + yeast extract interacted non-additively $(P=0.001)$ to reduce PUN. At $96 \mathrm{~h}$ post-challenge, AGP pigs had lower PUN $(P=0.02)$ and higher duodenal $(P=0.03)$, jejunal $(P=0.01)$ and ileal $(P=0.07)$ villus height than $C C$ pigs. In addition, enzymes + yeast extract interacted additively and non-additively to reduce ileal IFN- $\gamma(P<0.0001)$ and IL-10 $(P=0.012)$ expression, respectively. Generally, no differences $(P>0.10)$ were observed between AGP and enzymes + yeast extract pigs on other measured parameters except for the downregulation of ileal IFN- $\gamma(P<0.0001)$ and TNF- $\alpha(P=0.003)$ in enzymes + yeast extract pigs at $96 \mathrm{~h}$ post-challenge.
\end{abstract}

Conclusions: The LPS challenged piglets receiving enzymes + yeast extract showed beneficial responses in gut structure and immunity commensurate with those receiving antibiotics, though the latter had better overall growth performance.

Keywords: Antimicrobial growth promoter, Feed enzymes, Growth performance, Immunity, Nucleotides, Piglets

\footnotetext{
* Correspondence: Martin_Nyachoti@umanitoba.ca

'Department of Animal Science, University of Manitoba, 201-12 Dafoe Road,

Winnipeg, MB R3T 2N2, Canada

Full list of author information is available at the end of the article
} 


\section{Background}

Following the ban on sub-therapeutic use of antimicrobial growth promoters (AGP) in animal feed in the European Union [1] and the rising pressure for the same action in USA and Canada [2], the need for potential antibiotic alternatives that can promote piglet growth and health has intensified. Yeast extracts contain various bioactive compounds including nucleotides and cell wall polysaccharides (specifically $\beta$-glucan and $\alpha$-mannan) that are considered beneficial to the growth and gut health of piglets [3], hence yeast extracts have been considered to be a potential in-feed antibiotic alternative. Owing to the presence of various bioactive compounds in yeast extracts, the mechanism by which yeast extracts impact piglet growth and gut health is multifaceted. The main advantage of using yeast extracts as a feed additive is their affordability, a factor which may have less impact on feed cost when compared with the pure sources of its constituent bioactive compounds, thereby facilitating their adoption in the animal feed industry.

Supplementation of yeast extracts rich in nucleotides in piglet starter diets is deemed prudent in replenishing the nucleotide pool sourced from sow milk before weaning [4]. Nucleotides have been suggested to be "conditionally essential" nutrients during early weaning [5] because weaned pigs undergo rapid growth of tissue and organ systems, a process that is heavily dependent on availability of DNA, RNA, and ATP energy, whose synthesis depends on availability of nucleotides. The piglet enterocytes and immune cells have a high rate of replication but this is hampered by their limited capacity for de novo synthesis of nucleotides [6], the low concentration of nucleotides in compounded feed [7], and low voluntary feed intake by the piglet due to the transition from liquid to solid feed [8]. This may result in gut atrophy and slow maturation of both the digestive and immune systems, which determines the ability of the piglet to utilize nutrients for growth and to combat pathogens [8].

Supplementation of yeast extracts has been shown to have an immunostimulating effect, which is associated with $\beta$-glucans and $\alpha$-mannans present in yeast cell wall. For instance, it has been reported that yeast $\beta$-glucans prevent the elevation in pro-inflammatory cytokines while enhancing the production of anti-inflammatory cytokines when piglets immune system was challenged with lipopolysaccharide (LPS) [9] or Escherichia coli [10], whereas supplementing yeast-derived $\alpha$-mannans in piglet diets has been associated with improved weight gain and feed efficiency, and enhanced function of macrophages in the intestinal lamina propria [11].

It has been suggested that carbohydrases enhance gut health by hydrolyzing complex non-starch polysaccharides (NSP), thereby not only increasing nutrient availability but also inducing a prebiotic effect by releasing fermentable oligosaccharides that are utilized by host gut microbiota as an energy source [12-14]. There is a paucity of studies that simultaneously compare the effects of yeast extracts with AGP or multi-enzyme mixtures supplementation on growth performance and gut health of weaned piglets in response to an inflammatory challenge. Since yeast extracts contain nucleotides and cell wall polysaccharides that are considered to enhance the maturation of the digestive and immune systems of piglets [15], it was hypothesized that given an immune challenge, piglets receiving supplemental yeast extract will have well-balanced immune responses that suppress potentially harmful inflammation compared to challenged control pigs. Consequently, the suppression of harmful inflammation will prevent gut atrophy, encourage voluntary feed intake, and mitigate growth stasis. Moreover, it was hypothesized that a simultaneous supplementation of yeast extract and enzymes will have a synergistic effect of enhancing growth performance of the immune-challenged piglet. Therefore, in the current study, the aim was to determine the response of piglets receiving $0.1 \%$ yeast extract without or with enzymes compared with AGP to an immune system challenge with $E$. coli lipopolysaccharide (LPS) on growth performance, immune status, and gut structure during the immediate post-weaning period.

\section{Methods}

All experimental procedures were reviewed and approved by the University of Manitoba Animal Care Committee, and pigs were handled in accordance with the guidelines described by the Canadian Council on Animal Care [16].

\section{Animals and experimental design}

Thirty-six [Duroc $\times($ Yorkshire $\times$ Landrace $)]$ male and female piglets weaned at $21 \mathrm{~d}$ and with an initial average body weight of $6.89 \pm 0.5 \mathrm{~kg}$ were used in an 11-d study. Pigs were individually housed in pens in an environmentally controlled nursery building. Each pen was equipped with a feeder, a nipple drinker, and plasticcovered expanded metal floors. The room temperature was maintained at $29 \pm 1{ }^{\circ} \mathrm{C}$ throughout the study.

On d 1, pigs were randomly assigned to six treatments based on the initial body weight resulting in six replications per treatment. Treatments included: (1) non-challenged control (NCC; pigs fed the basal diet and injected with sterile saline on d 7); (2) LPSchallenged control (CC; pigs fed the basal diet and challenged by injection with E. coli LPS on d 7); (3) CC + AGP (pigs fed the basal diet supplemented with an antibiotic growth promoter (AGP) and challenged with E. coli LPS on d 7); (4) CC + yeast extract (pigs fed the basal diet supplemented with the yeast extract and challenged with $E$. coli LPS on d 7); (5) CC + enzymes (pigs fed the basal diet supplemented with feed enzymes and challenged with $E$. 
coli LPS on d 7); and (6) CC + enzymes + yeast extract (pigs fed the basal diet supplemented with enzymes and yeast extract, and challenged with E. coli LPS on d 7). The LPS (E. coli serotype 055: B5; Sigma Chemical Inc., St Louis, MO, USA) was dissolved in sterile saline and administered intramuscularly at $60 \mu \mathrm{g} / \mathrm{kg}$ body weight, whereas an equivalent amount of sterile saline was administered to NCC pigs. The LPS dosage of $60 \mu \mathrm{g} / \mathrm{kg}$ body weight was based on findings of Rakhshandeh and de Lange [17], which evaluated models of immune system stimulation in pigs and reported that an intramuscular injection of LPS at $60 \mu \mathrm{g} / \mathrm{kg}$ body weight can induce a relatively mild immune system stimulation that can be used to study how nutritional interventions interact with the immune system of pigs.

The basal diet (Table 1) was formulated to meet or exceed the National Research Council [18] requirements for all nutrients. The yeast extract supplement, Maxi-Gen Plus, was supplied by Canadian Bio-systems Inc. (Calgary, $\mathrm{AB}$, Canada) and contained cell wall polysaccharides (21.6 \%), CP (32.7\%), carbohydrates (14.3\%) and a mixture of five nucleotides (1.1\%; adenosine monophosphate, cytosine monophosphate, inosine monophosphate, uridine monophosphate and guanosine monophosphate. The AGP supplement, Aureomycin (Pfizer Inc., New York City, NY, USA), supplied 0.10 g chlortetracycline, $0.10 \mathrm{~g}$ sulfamethazine and $0.05 \mathrm{~g}$ penicillin per $\mathrm{kg}$ of feed. The multi-carbohydrase enzymes supplement, Superzyme-OM (Canadian Bio-systems Inc., Calgary, $\mathrm{AB}$, Canada), supplied $2800 \mathrm{U}$ of cellulase, $400 \mathrm{U}$ of mannanase, $50 \mathrm{U}$ of galactanase, $1000 \mathrm{U}$ of xylanase, $600 \mathrm{U}$ of glucanase, $2500 \mathrm{U}$ of amylase and $200 \mathrm{U}$ of protease per $\mathrm{kg}$ of diet. All the supplements were topdressed to the basal diet.

From $\mathrm{d} 1$ to 7 and 9 to 11 , pigs had free access to feed and water but were pair-fed for $48 \mathrm{~h}$ (d 7 to 9) after LPS or sterile saline injection by restricting the feed allowance of all pigs to $4 \%$ of their body weight so as to exclude the possible effects of LPS-induced food intake reduction on gastrointestinal characteristics of the pigs. Feed disappearance and body weight were recorded on $\mathrm{d}$ 7 and 11 on pen basis.

\section{Blood sampling and rectal temperature measurement}

Whole blood samples $(10 \mathrm{~mL}$ per pig) were collected via jugular vein puncture into ethylenediaminetetraacetic acid tubes on d 7 (before LPS challenge), and after 6, 48 and $96 \mathrm{~h}$ post LPS or saline injection and were placed on ice until they were processed further. In addition, on d 7 (before LPS challenge) and after $6 \mathrm{~h}$ post LPS or saline injection, rectal temperature of each pig was measured and 10-mL blood sample from each pig was collected into a non-heparinized Vacutainer tube (Becton Dickinson, Rutherford, NJ) and incubated
Table 1 Composition of the basal diet, as-fed basis

\begin{tabular}{|c|c|}
\hline Item & Percent \\
\hline \multicolumn{2}{|l|}{ Ingredient } \\
\hline Corn & 25.25 \\
\hline Wheat & 19.00 \\
\hline Soybean meal & 20.00 \\
\hline Canola meal & 5.00 \\
\hline Fish meal-H & 5.00 \\
\hline Dried whey & 20.00 \\
\hline Vegetable oil & 3.00 \\
\hline Limestone & 0.83 \\
\hline Monocalcium phosphate & 0.14 \\
\hline lodized salt & 0.26 \\
\hline Vitamin-trace mineral premix ${ }^{a}$ & 1.00 \\
\hline L-Lys $\mathrm{HCl}$ & 0.35 \\
\hline DL-Methionine & 0.10 \\
\hline Threonine & 0.07 \\
\hline \multicolumn{2}{|l|}{ Calculated nutrient content } \\
\hline $\mathrm{DE}, \mathrm{kcal} / \mathrm{kg}$ & 3573 \\
\hline $\mathrm{CP}, \%$ & 22.3 \\
\hline $\mathrm{Ca}, \%$ & 0.80 \\
\hline Total P, \% & 0.65 \\
\hline Available P, \% & 0.43 \\
\hline SID Lys, \% & 1.36 \\
\hline SID Met, \% & 0.43 \\
\hline SID Thr, \% & 0.79 \\
\hline \multicolumn{2}{|l|}{ Analyzed composition } \\
\hline $\mathrm{CP}, \%$ & 23.5 \\
\hline $\mathrm{Ca}, \%$ & 0.86 \\
\hline Total P, \% & 0.77 \\
\hline
\end{tabular}

aprovided the following per kilogram of complete diet: $9000 \mathrm{IU}$ of vitamin A; $1500 \mathrm{IU}$ of vitamin $\mathrm{D}_{3} ; 18 \mathrm{mg}$ of vitamin $\mathrm{E} ; 1.5 \mathrm{mg}$ of vitamin $\mathrm{K} ; 250 \mathrm{mg}$ of choline; $30 \mathrm{mg}$ of niacin; $27.5 \mathrm{mg}$ of calcium pantothenate; $9.4 \mathrm{mg}$ of riboflavin; $2 \mathrm{mg}$ of pyridoxine; $25 \mu \mathrm{g}$ of cyanocobalamin; $80 \mu \mathrm{g}$ of biotin; $0.5 \mathrm{mg}$ of folic acid; $18 \mathrm{mg}$ of Cu from copper sulfate, $110 \mathrm{mg}$ of $\mathrm{Zn}$ from zinc oxide, $0.2 \mathrm{mg}$ of I from calcium iodide, $110 \mathrm{mg}$ of Fe from ferrous sulfate, $50 \mathrm{mg}$ of $\mathrm{Mn}$ from manganese dioxide, and $0.3 \mathrm{mg}$ of Se from sodium selenite

at room temperature for $1 \mathrm{~h}$ before being centrifuged at $3000 \times g$ for $10 \mathrm{~min}$ at $4{ }^{\circ} \mathrm{C}$ to obtain serum. Serum samples were stored at $-80^{\circ} \mathrm{C}$ until required for analysis.

\section{Ileal, duodenal and jejunal tissue sampling}

On $\mathrm{d} 11$, that is $96 \mathrm{~h}$ post-challenge, all pigs were euthanized. A $5 \mathrm{~cm}$ section of duodenum, ileum and jejunum was fixed by immersion in $10 \%$ buffer neutral formalin, whereas $5 \mathrm{~g}$ samples of ileum were also collected, stored in RNA later solution (Qiagen, Hilden, Germany), and thereafter stored at $-80{ }^{\circ} \mathrm{C}$ until required for analysis. 


\section{Sample preparation and chemical analyses}

Dietary samples were processed and analyzed for $\mathrm{CP}, \mathrm{Ca}$ and total $\mathrm{P}$. Crude protein $(\mathrm{N} \times 6.25)$ was determined according to method 990.03 of AOAC [19] using a combustion analyzer (model CNS-2000; Leco Corp., St. Joseph, MI, USA). Dietary total Ca and P were analyzed following AOAC [19] procedures (method 990.08) using a Varian inductively coupled plasma mass spectrometer (Varian Inc., Palo Alto, CA).

\section{Histomorphology measurements}

The formalin-fixed duodenum, ileum and jejunum tissues were processed at the Veterinary Diagnostic Services Laboratory (Winnipeg, Manitoba, Canada). Villus height and crypt depth were measured at $10 \times$ magnification using Axiostar Plus microscope (Carl Zeiss, Oberkochen, Germany) equipped with a camera (Canon Canada Inc., Mississauga, Ontario, Canada) and Image software (National Institutes of Health, Bethesda, MD) in at least 15 well oriented villus and crypt columns. The villus height/crypt depth ratio was calculated.

\section{Blood cell counts and plasma urea nitrogen (PUN) measurement}

Whole blood samples were sent to the Manitoba Veterinary Services Laboratory (Winnipeg, MB, Canada) for complete blood count and PUN analysis. Complete blood count was measured using an automated analyzer (Orthoclinical Johnson \& Johnson VITROS 250 Chemistry System; Diamond Diagnostics, Holliston, MA), whereas PUN was measured using a Technicon Autoanalyzer System (Technicon Autoanalyzer Systems, Tarrytown, NY). Both analyses were measured in duplicate.

\section{Serum TNF- $a$ and IL-10}

Serum samples were used to measure the concentration of IL-10 and TNF- $\alpha$ using the quantitative sandwich enzyme-linked immunosorbent assay technique using porcine IL-10 and TNF- $\alpha$ immunoassay kits (R \& D Systems, Inc., Minneapolis, $\mathrm{MN}$ ) according to the manufacturer's instructions. The optical densities were read on a spectrophotometer (Soft Max Pro 3.1.1; Molecular Devices, Abingdon, Oxfordshire, UK). For each cytokine, the absorbance was measured at $450 \mathrm{~nm}$ with the correction wavelength set at $540 \mathrm{~nm}$. Cytokine concentrations were calculated from standards using a 4-parameter logistic curve fit.

\section{Total RNA extraction and reverse transcription}

Total RNA of ileal tissue samples was extracted for the determination of expression profiles of immune responserelated cytokines. Briefly, approximately $100 \mathrm{mg}$ of tissue sample was placed in a tube containing $0.5 \mathrm{~mL}$ beads and $1 \mathrm{~mL}$ TRIZOL reagent (Invitrogen Canada Inc.,
Burlington, Ontario, Canada) and subjected to bead beating with PowerLyzer (MO BIO Laboratories, Inc., Canada) for $2 \mathrm{~min}$ at homogenization level of $2500 \mathrm{psi}$, and then chilled on ice for $5 \mathrm{~min}$. The above procedure was repeated once. Total RNA was then extracted, washed, and eluted following the manufacturer's instructions for the TRIZOL reagent. RNA concentration and purity was measured using an ND-1000 spectrophotometer (NanoDrop Technologies, Wilmington, DE, USA). To remove genomic DNA contamination, total RNA was treated with DNase I according to the manufacturer's protocol. Two micrograms of total RNA with an optical density 260/280 ratio between 1.8 and 2.0 was used for cDNA synthesis using a High Capacity cDNA Reverse transcription Kit (Applied Biosystems, Foster City, CA, USA) with RNase inhibitor according to the manufacturer's instructions.

\section{Real-time PCR}

Real-time PCR for cDNA templates was carried out using a Bio-Rad CFX Real-time system (BioRad, Hercules, CA, USA). Each reaction mixture was run in duplicate using optical 96-well reaction plates (BioRad, Hercules, CA, USA). Each amplification reaction was carried out with $12.5 \mu \mathrm{L}$ of iTaq SYBR Green Supermix (BioRad, Hercules, CA, USA) mixed with $1 \mu \mathrm{L}$ of each primer set of interferon gamma (IFN- $\gamma$ ), tumor necrosis factor- $\alpha$ (TNF- $\alpha$ ), interleukin (IL)-1 $\beta$, IL-10, IL-6, and beta-actin (Table 2), $1 \mu \mathrm{L}$ of cDNA and $9.5 \mu \mathrm{L}$ of nuclease-free water. Negative controls were created by replacing cDNA with nucleasefree water. Amplification consisted of initial denaturation for $5 \mathrm{~min}$, followed by 40 cycles of denaturation at $95{ }^{\circ} \mathrm{C}$ for $15 \mathrm{~s}$, primer annealing at their individual optimal temperatures (Tables 2 and 3) for $30 \mathrm{~s}$, and an extension step at $72{ }^{\circ} \mathrm{C}$ for $30 \mathrm{~s}$. After the amplification, a melting curve analysis with a temperature gradient of $0.1{ }^{\circ} \mathrm{C}$ per second from 70 to $95{ }^{\circ} \mathrm{C}$ was performed to confirm that only specific products were amplified.

\section{Statistical analysis}

All data were analyzed using the Mixed procedure of SAS (SAS Inst., Inc., Cary, NC). A $2 \times 2$ factorial analysis of variance was conducted to compare yeast extract and enzymes treatments to determine synergistic effects of yeast extract and enzymes. Preplanned contrasts were used to compare CC with NCC to determine the LPS effect and to compare CC with other treatments, AGP with the yeast extract and AGP with enzymes to determine the effect of the supplements before and after LPS challenge. For all data analyses, significance was defined as $P<0.05$ and $0.05<P<0.10$ was considered a trend. 
Table 2 Primers used for qPCR analysis of immune cytokines

\begin{tabular}{|c|c|c|c|c|}
\hline Gene $^{a}$ & GenBank reference no. & Amplicon size, bp & $\mathrm{T}_{\mathrm{m}}{ }^{\mathrm{b}},{ }^{\circ} \mathrm{C}$ & Primer sequence $\left(5^{\prime} \rightarrow 3^{\prime}\right)$ \\
\hline$\overline{I F N-\gamma}$ & NM_213948.1 & 231 & 60 & $\begin{array}{l}\text { F: GGCCATTCAAAGGAGCATGG } \\
\text { R: GCTCTCTGGCCTTGGAACAT }\end{array}$ \\
\hline$I L-1 \beta$ & NM_214055.1 & 131 & 60 & $\begin{array}{l}\text { F: GCCCATCATCCTTGAAACGTG } \\
\text { R: GGAGAGCCTTCAGCATGTGT }\end{array}$ \\
\hline $\mathbb{L L}-6$ & NM_214399.1 & 149 & 60 & $\begin{array}{l}\text { F: TAAGGGAAATGTCGAGGCCG } \\
\text { R: TCCACTCGTTCTGTGACTGC }\end{array}$ \\
\hline $\mathbb{L L}-10$ & NM_214041.1 & 179 & 60 & $\begin{array}{l}\text { F: TCCGACTCAACGAAGAAGGC } \\
\text { R: AACTCTTCACTGGGCCGAAG }\end{array}$ \\
\hline TNF-a & NM_214022.1 & 120 & 60 & $\begin{array}{l}\text { F: ATTCAGGGATGTGTGGCCTG } \\
\text { R: CCAGATGTCCCAGGTTGCAT }\end{array}$ \\
\hline$\beta$-actin & XM_005670976.1 & 179 & 60 & $\begin{array}{l}\text { F: CGAGGCTCAGAGCAAGAGAG } \\
\text { R: GGTTGGCCTTAGGGTTCAGG }\end{array}$ \\
\hline
\end{tabular}

${ }^{a}$ IFN- $y$ interferon gamma, TNF- $a$ tumor necrosis factor- $a$, IL interleukin

${ }^{\mathrm{b}}$ Annealing temperature

\section{Results}

\section{Growth performance}

During $\mathrm{d} 1$ to 7 (pre-challenge), all piglets appeared healthy and no incidence of diarrhea was observed. In addition, there was no difference in ADG and gain/ feed ratio (G:F) among treatments except that LPSchallenged AGP pigs tended to have higher ADFI than LPS-challenged pigs receiving the yeast extract $(P=0.06$; Table 3$)$. Approximately $1 \mathrm{~h}$ post-LPS injection, piglets receiving LPS injection irrespective of the dietary treatment began to vomit, became somnolent and developed diarrhea. The piglets recovered from vomiting, somnolence and diarrhea between 24 and $48 \mathrm{~h}$ post-LPS injection. During $\mathrm{d} 7$ to 11 (post-challenge), compared with $\mathrm{CC}$ pigs, NCC pigs had higher ADG $(P=0.001)$ and ADFI $(P=0.003)$ and tended to have higher G:F $(P=0.07)$, whereas LPS-challenged pigs receiving AGP tended to have higher ADG $(P=$ 0.07 ). Overall ( $\mathrm{d} 1$ to 11 ), pigs receiving enzymes irrespective of the yeast extract had higher body weight $(P=0.048)$ and ADG $(P=0.017)$ than pigs not receiving enzymes. Compared to NCC pigs, LPSchallenge resulted in a $13 \%$ loss in body weight $(P=$ $0.02), 56 \%$ reduction in ADG $(P=0.004)$, a $37 \%$ reduction in ADFI $(P=0.02)$ and a $26 \%$ reduction in G:F $(P=0.02)$ of CC pigs. Compared to CC pigs, supplementation of AGP improved body weight $(P=0.02)$, ADG $(P=0.004)$, ADFI $(P=0.03)$ and G:F $(P=0.01)$. In addition, LPS-challenged pigs receiving AGP had higher body weight $(P=0.04)$ and ADG $(P=0.03)$ than LPS-challenged pigs receiving the yeast extract and tended to have higher ADFI than LPS-challenged pigs receiving the yeast extract $(P=0.06)$ or enzymes + yeast extract $(P=0.08)$. There were no differences between AGP and enzymes + yeast extract pigs on ADG and G:F.

\section{Plasma urea $\mathrm{N}$ content and blood cells count}

No effect of dietary treatment was observed for PUN pre-challenge (Table 4). After $6 \mathrm{~h}$ post-challenge, pigs receiving yeast extract irrespective of enzymes had lower PUN $(P=0.03)$ than pigs not receiving yeast extract, CC pigs had higher PUN than NCC pigs $(P=0.01)$ and LPSchallenged pigs receiving AGP $(P=0.02)$. After $48 \mathrm{~h}$ post-challenge, pigs receiving yeast extract irrespective of enzymes had lower PUN $(P=0.01)$ than pigs not receiving yeast extract, $C C$ pigs tended to have higher PUN than NCC pigs $(P=0.08)$ and LPS-challenged pigs receiving $\operatorname{AGP}(P=0.02)$. In addition, LPS-challenged pigs receiving the yeast extract tended to have lower PUN than those receiving AGP $(P=0.07)$. Moreover, an enzymes $\times$ yeast extract interaction $(P=0.001)$ was observed showing a non-additive effect of enzymes and the yeast extract in reducing the PUN of pigs. After $96 \mathrm{~h}$ post-challenge, $\mathrm{CC}$ pigs had higher PUN than NCC $(P=0.01)$ and LPS-challenged pigs receiving AGP $(P=0.02)$, whereas LPS-challenged pigs receiving enzymes + yeast extract tended to have higher PUN than those receiving AGP $(P=0.09)$. In addition, a tendency towards an enzymes $\times$ yeast extract interaction $(P=0.057)$ was observed showing a non-additive effect of enzymes and the yeast extract in reducing the PUN of pigs.

A tendency towards an enzymes $\times$ yeast extract interaction $(P=0.062)$ was observed pre-challenge showing a non-additive effect of enzymes and the yeast extract in increasing the white blood cell count of pigs. After $6 \mathrm{~h}$ post-challenge, pigs receiving yeast extract irrespective of enzymes had higher white blood cell count $(P=0.003)$ than pigs not receiving yeast extract, $C C$ pigs had lower white blood cell count than NCC $(P=0.0004)$. The LPS-challenged pigs receiving AGP tended to have higher white blood 
Table 3 Effect of supplementing AGP, feed enzymes (ENZ) or yeast extract (YE) without or with ENZ on growth performance of weaned piglets challenged with E. coli LPS

\begin{tabular}{|c|c|c|c|c|c|c|c|c|c|c|c|c|c|c|c|}
\hline \multirow[b]{2}{*}{ Item $^{a}$} & \multirow[b]{2}{*}{$N C C^{b}$} & \multicolumn{5}{|c|}{ LPS treatments $^{c}$} & \multirow[b]{2}{*}{ SEM } & \multicolumn{3}{|l|}{ Factorial $^{d}$} & \multicolumn{5}{|l|}{ Contrast } \\
\hline & & $\overline{\mathrm{AGP}}$ & $\mathrm{CC}$ & YE & ENZ & $\overline{Y E+E N Z}$ & & Main effect YE & Main effect ENZ & $\overline{Y E \times E N Z}$ & $\overline{N C C}$ vs CC & AGP vs CC & AGP VS YE & AGP vs ENZ & $A G P$ VS $Y E+E N Z$ \\
\hline $\mathrm{d} 1 \mathrm{BW}, \mathrm{kg}$ & 6.89 & 6.88 & 6.90 & 6.89 & 6.91 & 6.86 & 0.237 & NS & NS & NS & NS & NS & NS & NS & NS \\
\hline \multicolumn{16}{|l|}{ d 1 to 7} \\
\hline ADG, g/d & 159 & 212 & 150 & 140 & 196 & 164 & 31.7 & NS & NS & NS & NS & NS & NS & NS & NS \\
\hline ADFI, g/d & 191 & 225 & 168 & 160 & 214 & 172 & 24 & NS & NS & NS & NS & NS & 0.06 & NS & NS \\
\hline$G: F, g / g$ & 0.82 & 0.93 & 0.77 & 0.83 & 0.91 & 0.87 & 0.062 & NS & NS & NS & NS & NS & NS & NS & NS \\
\hline \multicolumn{16}{|l|}{ d 7 to 11} \\
\hline$A D G, g / d$ & 323 & 226 & 130 & 174 & 170 & 160 & 33.2 & NS & NS & NS & 0.001 & 0.07 & NS & NS & NS \\
\hline$A D F I, g / d$ & 366 & 288 & 214 & 229 & 264 & 249 & 29.8 & NS & NS & NS & 0.003 & NS & NS & NS & NS \\
\hline$G: F, g / g$ & 0.88 & 0.8 & 0.59 & 0.75 & 0.64 & 0.66 & 0.1 & NS & NS & NS & 0.07 & NS & NS & NS & NS \\
\hline \multicolumn{16}{|l|}{ d 1 to 11} \\
\hline BW, kg & 9.3 & 9.27 & 8.07 & 8.39 & 8.9 & 8.78 & 0.319 & NS & 0.048 & NS & 0.02 & 0.02 & 0.04 & NS & NS \\
\hline$A D G, g / d$ & 241 & 239 & 112 & 162 & 192 & 190 & 27.3 & NS & 0.017 & NS & 0.004 & 0.004 & 0.03 & NS & NS \\
\hline ADFI, g/d & 280 & 273 & 177 & 204 & 250 & 210 & 26.3 & NS & NS & NS & 0.02 & 0.03 & 0.06 & NS & 0.08 \\
\hline$G: F, g / g$ & 0.85 & 0.88 & 0.63 & 0.79 & 0.77 & 0.76 & 0.061 & NS & NS & NS & 0.02 & 0.01 & NS & NS & NS \\
\hline
\end{tabular}

${ }^{a} B W$ body weight, $A D G$ average daily gain, $A D F I$ average daily feed intake, G:F gain to feed ratio

${ }^{\mathrm{b}} \mathrm{NCC}$ non-challenged control pigs that were fed the basal diet and injected with sterile saline on $\mathrm{d} 7$

'Pigs fed the basal diet without any additive (CC challenged control) or with AGP, YE, ENZ or ENZ + YE and injected with E. coli LPS on d 7

${ }^{\mathrm{d}} P$-value for LPS + ENZ $\times$ LPS + YE interaction (CC, YE, ENZ and ENZ + YE) 
Table 4 Effect of supplementing AGP, feed enzymes (ENZ) or yeast extract (YE) without or with ENZ on PUN (mmol/L) and count of white blood cells (WBC, 10 $\left.{ }^{9} / \mathrm{L}\right)$, red blood cells (RBC, $\left.10^{12} / \mathrm{L}\right)$ and platelets $\left(10^{9} / \mathrm{L}\right)$ of weaned piglets challenged with E. coli LPS

\begin{tabular}{|c|c|c|c|c|c|c|c|c|c|c|c|c|c|c|c|}
\hline \multirow[b]{2}{*}{ Item } & \multirow[b]{2}{*}{$\mathrm{NCC}^{\mathrm{a}}$} & \multicolumn{5}{|c|}{ LPS treatments ${ }^{\mathrm{b}}$} & \multirow[b]{2}{*}{ SEM } & \multicolumn{3}{|l|}{ Factorial $^{c}$} & \multicolumn{5}{|l|}{ Contrast } \\
\hline & & AGP & CC & YE & ENZ & $\mathrm{YE}+\mathrm{ENZ}$ & & Main effect YE & Main effect ENZ & $Y E \times E N Z$ & NCC vs CC & AGP vs CC & AGP Vs YE & AGP vs ENZ & $A G P$ vs YE + ENZ \\
\hline \multicolumn{16}{|l|}{$\overline{P U N}$} \\
\hline Pre-challenge & 2.34 & 2.28 & 2.95 & 2.08 & 2.52 & 2.57 & 0.412 & NS & NS & NS & NS & NS & NS & NS & NS \\
\hline $6 \mathrm{~h}$ post-challenge & 2.12 & 2.58 & 4.18 & 2.5 & 3.42 & 2.6 & 0.478 & 0.03 & NS & NS & 0.01 & 0.02 & NS & NS & NS \\
\hline $48 \mathrm{~h}$ post-challenge & 2.16 & 1.93 & 2.97 & 1.24 & 1.6 & 1.83 & 0.285 & 0.01 & NS & 0.001 & 0.08 & 0.02 & 0.07 & NS & NS \\
\hline $96 \mathrm{~h}$ post-challenge & 1.66 & 1.78 & 3.2 & 2.1 & 2.55 & 2.77 & 0.384 & NS & NS & 0.057 & 0.01 & 0.02 & NS & NS & 0.09 \\
\hline \multicolumn{16}{|l|}{ WBC } \\
\hline Pre-challenge & 16.9 & 18 & 17.8 & 15 & 14.1 & 19.3 & 2.21 & NS & NS & 0.062 & NS & NS & NS & NS & NS \\
\hline $6 \mathrm{~h}$ post-challenge & 19.7 & 10.2 & 6.5 & 12.2 & 7.6 & 15.5 & 1.98 & 0.003 & NS & NS & 0.0004 & NS & NS & 0.07 & 0.07 \\
\hline $48 \mathrm{~h}$ post-challenge & 18.2 & 16.8 & 17.3 & 17.5 & 16.2 & 19.7 & 1.68 & NS & NS & NS & NS & NS & NS & NS & NS \\
\hline $96 \mathrm{~h}$ post-challenge & 19.6 & 16.7 & 16.9 & 16.3 & 14.5 & 18.2 & 1.3 & NS & NS & NS & NS & NS & NS & NS & NS \\
\hline \multicolumn{16}{|l|}{ RBC } \\
\hline Pre-challenge & 5.96 & 5.54 & 6.04 & 6.09 & 6.04 & 6.06 & 0.228 & NS & NS & NS & NS & NS & NS & NS & NS \\
\hline $6 \mathrm{~h}$ post-challenge & 5.91 & 5.68 & 6.01 & 6.62 & 6.33 & 5.97 & 0.255 & NS & NS & 0.090 & NS & NS & 0.01 & NS & NS \\
\hline $48 \mathrm{~h}$ post-challenge & 5.59 & 4.96 & 5.39 & 5.41 & 5.48 & 5.25 & 0.184 & NS & NS & NS & NS & NS & 0.07 & NS & NS \\
\hline $96 \mathrm{~h}$ post-challenge & 5.95 & 5.18 & 5.32 & 5.6 & 5.46 & 5.22 & 0.19 & NS & NS & NS & 0.02 & NS & NS & NS & NS \\
\hline \multicolumn{16}{|l|}{ Platelet } \\
\hline Pre-challenge & 429 & 534 & 450 & 483 & 447 & 415 & 44.8 & NS & NS & NS & NS & NS & NS & NS & NS \\
\hline $6 \mathrm{~h}$ post-challenge & 413 & 309 & 196 & 350 & 205 & 278 & 37.3 & 0.001 & NS & NS & 0.0002 & 0.04 & NS & NS & NS \\
\hline $48 \mathrm{~h}$ post-challenge & 445 & 345 & 350 & 338 & 322 & 345 & 29.9 & NS & NS & NS & 0.05 & NS & NS & NS & NS \\
\hline $96 \mathrm{~h}$ post-challenge & 449 & 446 & 386 & 520 & 427 & 507 & 61.3 & 0.06 & NS & NS & NS & NS & NS & NS & NS \\
\hline
\end{tabular}

${ }^{a} N C C$ non-challenged control pigs that were fed the basal diet and injected with sterile saline on $\mathrm{d} 7$

bigs fed the basal diet without any additive (CC challenged control) or with AGP, YE, ENZ or ENZ + YE and injected with E. coli LPS on d 7

${ }^{C} P$-value for LPS + ENZ $\times$ LPS + YE interaction (CC, YE, ENZ and ENZ + YE) 
cell count than those receiving enzymes $(P=0.07)$ and lower white blood cell count than those receiving enzymes + yeast extract $(P=0.07)$. After 48 and $96 \mathrm{~h}$ post-challenge, treatments had no effect on white blood cell count.

No effect of dietary treatment was observed for red blood cells count before LPS challenge. After $6 \mathrm{~h}$ post-challenge, LPS-challenged pigs receiving AGP had lower red blood cell count $(P=0.01)$ than challenged pigs receiving the yeast extract and a tendency towards an enzymes $\times$ yeast extract interaction $(P=$ 0.090) was observed showing a non-additive effect of enzymes and the yeast extract in decreasing the red blood cell count of pigs. After $48 \mathrm{~h}$ post-challenge, LPS-challenged pigs receiving AGP tended to have higher $(P=0.07)$ red blood cell count than challenged pigs receiving the yeast extract, whereas after $96 \mathrm{~h}$ post-challenge, compared to NCC pigs, red blood cell count was lower in CC pigs $(P=0.02)$.

No effect of dietary treatment was observed for platelet count pre-challenge. After $6 \mathrm{~h}$ post-challenge, pigs receiving yeast extract irrespective of enzymes had higher platelet count $(P=0.001)$ than pigs not receiving yeast extract. The platelet count of CC pigs was lower than of NCC pigs $(P=0.0002)$ and LPS-challenged pigs receiving AGP. After $48 \mathrm{~h}$ post-challenge, pigs receiving yeast extract irrespective of enzymes tended to have a higher platelet count $(P=0.06)$ than pigs not receiving yeast extract. The platelet count of CC pigs was lower $(P=0.05)$ than of NCC pigs and was not influenced by treatments after $96 \mathrm{~h}$ post-challenge.

\section{Duodenum, jejunum and ileum histomorphology}

After $96 \mathrm{~h}$ post-challenge, pigs receiving yeast extract irrespective of enzymes tended to have a higher duodenal villus height $(P=0.098)$ than pigs not receiving yeast extract. Pigs receiving enzymes irrespective of the yeast extract had higher duodenal villus height $(P=0.004)$ than pigs not receiving enzymes, whereas the duodenal villus height for CC pigs was lower than that of NCC $(P=$ $0.002)$ and LPS-challenged pigs receiving AGP $(P=0.03$; Table 5). The duodenal crypt depth for CC pigs was lower than that of NCC pigs $(P=0.02)$. Pigs receiving yeast extract irrespective of enzymes had higher jejunal villus height $(P=0.049)$ and jejunal VH:CD $(P=0.03)$ than pigs not receiving yeast extract, whereas pigs receiving enzymes irrespective of the yeast extract had higher jejunal villus height $(P=0.047)$ and tended to have higher jejunal $\mathrm{VH}: \mathrm{CD}(P=0.07)$ than pigs not receiving enzymes. In addition, $\mathrm{CC}$ pigs had shorter jejunal villus height than NCC pigs $(P<0.0001)$ and LPSchallenged pigs receiving AGP $(P=0.01)$. Moreover, compared with $\mathrm{CC}$ pigs, the jejunal $\mathrm{VH}: \mathrm{CD}$ ratio was higher in NCC $(P=0.0003)$ pigs and LPS-challenged pigs receiving AGP $(P=0.01)$. The ileal villus height of CC pigs was shorter than of NCC pigs $(P=0.04)$ and tended to be shorter than that of LPS challenged pigs receiving AGP $(P=0.07)$.

\section{Rectal temperature, serum and ileum cytokines}

Before LPS challenge, pigs receiving enzymes irrespective of the yeast extract tended to have higher rectal temperature $(P=0.06)$ than pigs not receiving enzymes, whereas no effect of treatments was observed for concentration of serum TNF- $\alpha$ and IL-10 (Table 6). After $6 \mathrm{~h}$ post-challenge, rectal temperature was higher in $\mathrm{CC}$ pigs $(P=0.003)$ compared with NCC pigs. In addition, pigs receiving yeast extract irrespective of enzymes had a lower concentration of serum TNF- $\alpha(P=0.001)$ and higher concentration of serum IL-10 $(P=0.004)$ than pigs not receiving yeast extract. Compared with CC pigs, the concentration of serum TNF- $\alpha$ was lower in NCC pigs $(P<0.0001)$ and LPS-challenged pigs receiving AGP $(P=0.07)$, whereas the serum IL-10 concentration was lower in NCC pigs $(P=0.001)$ but higher in LPSchallenged pigs receiving AGP $(P=0.02)$.

After $96 \mathrm{~h}$ post-challenge, pigs receiving yeast extract irrespective of enzymes had a lower expression of IFN $-\gamma$ $(P>0.0001)$, TNF- $\alpha(P=0.013), \mathrm{IL}-1 \beta(P=0.025)$ and IL$10(P=0.033)$ than pigs not receiving yeast extract. On the other hand, pigs receiving enzymes irrespective of the yeast extract had a lower expression of IL-1 $\beta(P=$ $0.001)$ and IL-10 $(P=0.019)$, and a tendency towards lower expression of TNF- $\alpha(P=0.099)$ than pigs not receiving enzymes. Compared to NCC pigs, the CC pigs had higher expression of ileal IFN- $\gamma(P=0.04)$. An enzymes $\times$ yeast extract interaction $(P<0.0001)$ was observed showing an additive effect of enzymes and the yeast extract in downregulating the expression of ileal IFN- $\gamma$ in LPS-challenged pigs. Compared with pigs receiving AGP, the ileal IFN- $\gamma$ expression was higher $(P=$ $0.008)$ in LPS-challenged pigs receiving enzymes but lower $(P<0.0001)$ in pigs receiving enzymes + yeast extract.

After $96 \mathrm{~h}$ post-challenge, the CC pigs had a higher expression of ileal TNF- $\alpha(P=0.0003)$ than NCC pigs. A tendency towards an enzymes $\times$ yeast extract interaction $(P=0.073)$ was observed showing a non-additive effect of enzymes and the yeast extract in downregulating the expression of ileal TNF- $\alpha$ in LPS-challenged pigs. Compared with LPS challenged pigs receiving AGP, TNF- $\alpha$ expression was lower in LPS-challenged pigs receiving yeast extract $(P=0.002)$, enzymes $(P=0.013)$ or enzymes + yeast extract $(P=0.003)$.

After $96 \mathrm{~h}$ post-challenge, compared with CC pigs, the expression of ileal IL-1 $\beta$ was lower in NCC pigs $(P=0.01)$ and in LPS-challenged pigs receiving AGP $(P=0.004)$. The CC pigs tended to have a higher 
Table 5 Effect of supplementing AGP, feed enzymes (ENZ) or yeast extract (YE) without or with ENZ on ileum, jejunum and duodenum histomorphology of weaned piglets after $96 \mathrm{~h}$ of challenge with E. coli LPS

\begin{tabular}{|c|c|c|c|c|c|c|c|c|c|c|c|c|c|c|c|}
\hline \multirow[b]{2}{*}{ Item $^{a}$} & \multirow[b]{2}{*}{$\mathrm{NCC}^{\mathrm{b}}$} & \multicolumn{5}{|c|}{ LPS treatments $^{c}$} & \multirow[b]{2}{*}{ SEM } & \multicolumn{3}{|l|}{ Factorial $^{d}$} & \multicolumn{5}{|l|}{ Contrast } \\
\hline & & $\overline{\mathrm{AGP}}$ & CC & YE & ENZ & $\mathrm{YE}+\mathrm{ENZ}$ & & Main effect YE & Main effect ENZ & $Y E \times E N Z$ & NCC vs CC & AGP vs CC & AGP vs YE & AGP vs ENZ & AGP vs YE + ENZ \\
\hline \multicolumn{16}{|l|}{ Duodenum, $\mu \mathrm{m}$} \\
\hline Villus height & 532 & 493 & 410 & 480 & 520 & 538 & 24.7 & 0.098 & 0.004 & NS & 0.002 & 0.03 & NS & NS & NS \\
\hline Crypt depth & 322 & 308 & 277 & 305 & 314 & 316 & 13.1 & NS & NS & NS & 0.02 & NS & NS & NS & NS \\
\hline $\mathrm{VH}: \mathrm{CD}$ & 1.65 & 1.61 & 1.50 & 1.58 & 1.68 & 1.70 & 0.088 & NS & NS & NS & NS & NS & NS & NS & NS \\
\hline \multicolumn{16}{|l|}{ Jejunum, $\mu \mathrm{m}$} \\
\hline Villus height & 465 & 400 & 293 & 385 & 385 & 412 & 26.3 & 0.049 & 0.047 & NS & $<.0001$ & 0.01 & NS & NS & NS \\
\hline Crypt depth & 277 & 269 & 255 & 275 & 282 & 273 & 13.2 & NS & NS & NS & NS & NS & NS & NS & NS \\
\hline $\mathrm{VH}: \mathrm{CD}$ & 1.70 & 1.50 & 1.15 & 1.40 & 1.37 & 1.51 & 0.092 & 0.03 & 0.07 & NS & 0.0003 & 0.01 & NS & NS & NS \\
\hline \multicolumn{16}{|l|}{ Ileum, $\mu \mathrm{m}$} \\
\hline Villus height & 329 & 323 & 272 & 294 & 308 & 306 & 18.8 & NS & NS & NS & 0.04 & 0.07 & NS & NS & NS \\
\hline Crypt depth & 265 & 259 & 244 & 233 & 268 & 249 & 13.6 & NS & NS & NS & NS & NS & NS & NS & NS \\
\hline VH:CD & 1.24 & 1.26 & 1.11 & 1.26 & 1.17 & 1.23 & 0.067 & NS & NS & NS & NS & NS & NS & NS & NS \\
\hline
\end{tabular}

${ }^{a} V H: C D$ villus height/crypt depth; means are averages of at least 15 well oriented villus and crypt columns

${ }^{\mathrm{b}} \mathrm{NCC}$ non-challenged control pigs that were fed the basal diet and injected with sterile saline on $\mathrm{d}$

CPigs fed the basal diet without any additive (CC challenged control) or with AGP, YE, ENZ or ENZ + YE and injected with E. coli LPS on d 7

${ }^{d} P$-value for LPS + ENZ $\times$ LPS + YE interaction (CC, YE, ENZ and ENZ + YE) 
Table 6 Effect of supplementing AGP, feed enzymes (ENZ) and yeast extract (YE) without or with ENZ on the rectal temperature ( ${ }^{\circ} \mathrm{C}$ ), concentration of serum (pg/mL) cytokines and fold changes $\left(\log _{2}\right)$ of ileal immune cytokines of weaned piglets challenged with E. coli LPS

\begin{tabular}{|c|c|c|c|c|c|c|c|c|c|c|c|c|c|c|c|}
\hline \multirow[b]{2}{*}{ Item } & \multirow[b]{2}{*}{$\mathrm{NCC}^{\mathrm{a}}$} & \multicolumn{5}{|c|}{ LPS treatments ${ }^{\mathrm{b}}$} & \multirow[b]{2}{*}{ SEM } & \multicolumn{3}{|l|}{ Factorial $^{c}$} & \multicolumn{5}{|l|}{ Contrast } \\
\hline & & AGP & $\mathrm{CC}$ & YE & ENZ & $Y E+E N Z$ & & Main effect YE & Main effect ENZ & $Y E \times E N Z$ & NCC vs CC & AGP vs CC & AGP vs YE & AGP vs ENZ & $A G P$ VS YE + ENZ \\
\hline \multicolumn{16}{|l|}{ Rectal temperature } \\
\hline Pre-challenge & 38.9 & 39.2 & 39.1 & 39.0 & 39.2 & 39.2 & 0.13 & NS & 0.06 & NS & NS & NS & NS & NS & NS \\
\hline $6 \mathrm{~h}$ post-challenge & 39.2 & 39.9 & 39.9 & 39.8 & 40.1 & 40.1 & 0.15 & NS & NS & NS & 0.003 & NS & NS & NS & NS \\
\hline \multicolumn{16}{|l|}{ Serum TNF-a } \\
\hline Pre-challenge & 98 & 88 & 96 & 77 & 102 & 93 & 9.3 & NS & NS & NS & NS & NS & NS & NS & NS \\
\hline $6 \mathrm{~h}$ post-challenge & 111 & 1032 & 1369 & 854 & 1621 & 933 & 120.8 & 0.001 & NS & NS & $<.0001$ & 0.07 & 0.85 & 0.003 & NS \\
\hline \multicolumn{16}{|l|}{ Serum IL-10 } \\
\hline Pre-challenge & 18 & 16 & 29 & 22 & 36 & 27 & 15.1 & NS & NS & NS & NS & NS & NS & NS & NS \\
\hline $6 \mathrm{~h}$ post-challenge & 16 & 157 & 99 & 153 & 86 & 156 & 15.3 & 0.004 & NS & NS & 0.001 & 0.02 & NS & NS & NS \\
\hline \multicolumn{16}{|c|}{ Ileum cytokines, 96 h post-challenge } \\
\hline $\mathrm{IFN}-\gamma$ & 1.00 & 1.54 & 1.46 & 1.51 & 2.15 & 0.54 & 0.152 & $<.0001$ & NS & $<.0001$ & 0.04 & NS & NS & 0.008 & $<.0001$ \\
\hline TNF-a & 1.00 & 2.52 & 2.40 & 1.37 & 1.60 & 1.41 & 0.244 & 0.013 & 0.099 & 0.073 & 0.0003 & NS & 0.002 & 0.013 & 0.003 \\
\hline $\mathbb{I L}-1 \beta$ & 1.00 & 0.95 & 1.63 & 1.02 & 0.77 & 0.58 & 0.154 & 0.025 & 0.001 & NS & 0.01 & 0.004 & NS & NS & NS \\
\hline IL-6 & 1.00 & 0.86 & 0.85 & 0.83 & 0.69 & 1.12 & 0.130 & NS & NS & NS & NS & NS & NS & NS & NS \\
\hline IL-10 & 1.00 & 0.60 & 1.31 & 0.74 & 0.71 & 0.76 & 0.123 & 0.033 & 0.019 & 0.012 & 0.09 & 0.0003 & NS & NS & NS \\
\hline
\end{tabular}

${ }^{a} \mathrm{NCC}$ non-challenged control pigs that were fed the basal diet and injected with sterile saline on $\mathrm{d} 7$

${ }^{b}$ Pigs fed the basal diet without any additive (CC challenged control) or with AGP, YE, ENZ or ENZ + YE and injected with E. coli LPS on d 7

${ }^{C} P$-value for LPS + ENZ $\times$ LPS + YE interaction (CC, YE, ENZ and ENZ + YE) 
expression of ileal IL-10 $(P=0.09)$ than NCC pigs. An enzymes $\times$ yeast extract interaction $(P=0.012)$ was observed showing a non-additive effect of enzymes and the yeast extract in downregulating the expression of ileal IL-10 in LPS-challenged pigs. Compared with CC pigs, IL-10 expression was lower in LPS-challenged pigs receiving AGP $(P=0.0003)$.

\section{Discussion}

The AGP, yeast extract and enzymes supplements did not affect performance during the first $7 \mathrm{~d}$ of weaning. Sauer et al. [20] and Andrés-Elias et al. [21] supplemented 0.1 and $0.15 \%$ yeast extract in piglet starter diets, respectively, and reported no effect of yeast extract on growth performance. Between d 7 and 11 (post-challenge), the LPS challenge reduced ADG, ADFI and G:F of CC pigs. This observation is consistent with the findings of Liu et al. [22] and Liu et al. [23] showing that LPS challenge negatively impacts growth performance in pigs. Although none of the supplements was able to fully protect the pigs from weight loss or to increase their feed intake between $\mathrm{d} 7$ and 11, the LPS impact on ADG tended to be reduced in AGP receiving pigs compared with other LPS-challenged treatments. This beneficial effect of AGP on growth performance was further seen in the overall experimental period ( 1 to 11) with AGP pigs having better ADG, ADFI and GF than CC pigs, and tended to have better G:F than pigs supplemented with yeast extract. These observations suggest that AGP supplemented pigs had better recovery of weight and feed intake after LPS challenge than those supplemented with yeast extract. Weber et al. [24] and Skinner et al. [25] reported that AGP improves ADG during the nursery phase, whereas Wu et al. [26] reported that piglets receiving infeed AGP and challenged with enterotoxigenic E. coli had higher ADG and G:F than control. Niewold [27] suggested that AGP improve gut health and growth performance of livestock by reducing the gut pathogen load and competition for nutrients between the host and gut microbes. This effect may also be associated with the immunoregulatory role of AGP [28]. Although enzymes supplementation tended to improve ADG ( 1 to 11 ), there was no synergistic effect between yeast extract and enzymes on ADG.

The reduced white blood cell and platelet counts in CC pigs is due to LPS induced autoimmunity and suggests an increased incidence or severity of infection $[29,30]$. Platelets play a crucial role in blood clotting and as the first responders to sites of vascular injury or pathogen invasion, platelets play multiple roles in the modulation of both innate and adaptive immunity thereby boosting host defense against infection [30]. The observation that LPSchallenged pigs receiving yeast extract maintained higher white blood cell and platelet count than CC pigs and higher red blood cell count than LPS-challenged pigs receiving AGP at $6 \mathrm{~h}$ post-challenge suggests that yeast extract supplementation either had a role in preventing blood cells death or sustained moderate blood cell formation during the challenge period.

A $100 \mu \mathrm{g} / \mathrm{kg}$ dosage of E. coli LPS has been shown to induce gut injury in pigs $[23,31]$. In the present study, gut injury was observed in piglets that received $60 \mu \mathrm{g} / \mathrm{kg}$ of $E$. coli LPS. Supplementing yeast extract to pigs without or with enzymes reduced villus atrophy in the jejunum and duodenum, and the villus height/crypt depth ratio in the jejunum when compared with the non-challenged control pigs, and the effect was similar to that of AGP supplementation. The increase in villus height and villus/ crypt ratio indicates an improvement in the digestion and absorption of nutrients [31, 32]. Enterocytes have limited capacity for de novo nucleotides synthesis [33, 34] and thus the increased pool of dietary nucleotides by yeast extract supplementation promoted intestinal tissue growth and development. In addition, pathogens with mannosespecific type-1 fimbriae, such as E. coli and Salmonella, bind with the $\alpha$-mannans instead of attaching to intestinal epithelial cells, which may reduce inflammation that leads to intestinal villi atrophy [35].

Injection of LPS induces fever in pigs by stimulating the production of cytokines such as IL-1, TNF- $\alpha$ and IFN- $\gamma$, which are regarded as endogenous mediators of fever [36]. In this study, $6 \mathrm{~h}$ post-challenge CC pigs showed a significant rise in body temperature compared to NCC pigs as also observed by Pi et al. [37] and none of the supplements protected the pigs from fever development. The concentration of serum TNF- $\alpha$ and IL-10 were measured as indicators of systemic pro- and antiinflammation responses, respectively. Pigs receiving AGP or yeast extract without or with enzymes had less concentration of serum TNF- $\alpha$ and higher concentration of IL-10 than CC pigs, hence, implying that AGP and enzymes + yeast extract supplementation lowered pro-inflammation of the immune system. The ileum immune response was also influenced by both LPS and the supplements. The observed upregulation of ileal TNF- $\alpha$ and IL- $1 \beta 96$ h postchallenge in the $\mathrm{CC}$ pigs compared to NCC pigs suggests development of inflammation in CC pigs, which if prolonged leads to tissue damage such as the observed villus atrophy in these pigs [38]. In contrast, pigs in the yeast extract supplemented treatments had downregulated levels of expression of these pro-inflammatory cytokines thus suggesting that the yeast extract induced beneficial immunoregulatory responses post-challenge that was evidenced by lower expression of TNF- $\alpha$ and IL- $1 \beta$, and consequently that of IL-10 compared to the LPS-challenged control group. The overproduction of proinflammatory cytokines is associated with anorexia development, and may explain the observed reduction in ADFI in LPSchallenged pigs in this study $[39,40]$. 
In the present study, LPS-challenged control pigs had higher PUN than non-challenged control pigs. This is consistent with the study of Webel et al. [41] reporting that LPS challenge increases the PUN level in piglets due to muscle proteolysis as a result of increased inflammation. Owusu-Asiedu et al. [42] suggested that the released amino acids due to inflammation may be channeled to the liver to synthesize acute phase proteins and/or to serve as an energy source. Supplementing yeast extract without or with enzymes had similar effects as AGP in reducing PUN level compared with the LPS-challenged control. The reduction in PUN level is an indicator of reduced muscle protein breakdown [41] and is consistent with the observed reduced production of proinflammatory cytokines in the yeast extract and AGP receiving pigs. These observations suggest that supplementing yeast extract or AGP was beneficial to piglets and reduced the severity of the LPS challenge. Such a response may promote efficiency in utilization of dietary amino acids for proteinaceous tissue growth [39].

Taken together, after the immune system stimulation using E. coli LPS, the growth performance, platelets count, villus height of the jejunum and duodenum, and immune status of LPS-challenged control pigs was negatively affected compared with the non-challenged control. Compared to LPS-challenged control, supplementing yeast extract + enzymes lowered and increased the expression of ileal IFN- $\gamma$ and IL-10, respectively, and improved histomorphological measurements but did not affect growth performance. Most of the observed enzymes $\times$ yeast extract interactions or tendencies towards interaction were non-additive except that of lowering ileal IFN- $\gamma$. The most pronounced beneficial effects of yeast extract supplementation were on lowering PUN, villus atrophy, and levels of pro-inflammatory cytokines, and maintaining blood cell counts close to that of non-challenged control pigs.

The immunomodulating effect of the yeast extract is multifaceted and may be associated with the nucleotides and cell wall polysaccharides present in the yeast extract. In response to the inflammatory challenge, the nucleotides sourced from the yeast extract can be channeled to influence the development and maturation of important tissues of the immune system and the intestinal mucosa. This supports the suggestion by Gaskins et al. [43] that the weaned pig first invests substantially in defensive efforts to sequester gut microbes away from the epithelial surface, and second to quickly mount immune responses against microbes that breach epithelial defenses. This re-direction of nutrients from growth towards fortification of the immune system and maturation of gut structures may explain why beneficial responses on growth performance may not be observed within a short term of supplementing the yeast extract nucleotides. However, a faster maturation of the gut and immune system tissues, may in the long-run support faster growth of the pig, hence the effect of nucleotides may be long-lasting. On the other hand, there is evidence that yeast $\beta$-glucans are associated with downregulation and upregulation of the expression of pro-inflammatory and anti-inflammatory cytokines, respectively, when piglets immune system is challenged with LPS [9] or E. coli [10], and that yeast-derived $\alpha$ mannans has been associated with improved enhanced function of macrophages in the intestinal lamina propria [11]. The yeast cell wall polysaccharides may also provide binding sites for pathogens hence mediating their elimination from the gut [44].

\section{Conclusions}

In conclusion, LPS-challenged piglets fed diets supplemented with yeast extract without or with enzymes expressed similar beneficial responses as those fed diets with AGP in terms of lowering PUN concentration, reducing duodenal and ileal villi atrophy, and downregulating serum and ileal proinflammatory cytokines. This suggests that supplementation of the yeast extract was associated with promotion of the health of piglets during the immediate post-weaning period.

\section{Abbreviations}

ADFI: Average daily feed intake; ADG: Average daily gain; AGP: Antimicrobial growth promoters; CP: Crude protein; G:F: Gain/feed ratio; IFN-

Y: Interferon gamma; IL: Interleukin; LPS: E. coli lipopolysaccharide;

PUN: Plasma urea nitrogen; TNF-a: Tumor necrosis factor alpha

\section{Acknowledgements}

The authors sincerely thank Dr. Hossain M.M for reviewing the manuscript, Robert Stuski for assisting in animal husbandry and Atanas Karamanov for assisting in processing and analysis of samples.

\section{Funding}

This study was supported by funds from Natural Sciences and Engineering Research Council of Canada, Canadian Bio-Systems Inc., (Calgary, AB, Canada) and Manitoba Pork Council. Except for Canadian Bio-Systems Inc., the other funders had no role in the design of the study, collection, analysis, and interpretation of data and in writing of the manuscript.

\section{Availability of data and materials}

The datasets supporting the conclusions of this article are included within the article.

\section{Authors' contributions}

All authors participated in the design of the experiment. SMW and FY carried out the animal studies. FY carried out the qPCR analysis. SMW carried out statistical analysis and drafted the manuscript. All authors participated in the interpretation of the data, review and approval of the final manuscript.

\section{Competing interests}

The authors declare that they have no competing interests.

Consent for publication

Not applicable. 


\section{Ethics approval and consent to participate}

The experimental protocol used in this study, including animal management, housing, and slaughter procedures, was approved by the University of Manitoba Animal Care Committee.

\section{Author details}

'Department of Animal Science, University of Manitoba, 201-12 Dafoe Road, Winnipeg, MB R3T 2N2, Canada. ${ }^{2}$ Canadian Bio-systems Inc., Calgary, AB T2C 0J7, Canada. ${ }^{3}$ Atlantic Veterinary College, University of Prince Edward Island, Charlottetown, PE C1A 4P3, Canada.

\section{Received: 6 April 2016 Accepted: 19 October 2016} Published online: 03 November 2016

\section{References}

1. Casewell M, Friis C, Marco E, McMullin P, Phillips I. The European ban on growth-promoting antibiotics and emerging consequences for human and animal health. J Antimicrob Chemother. 2003:52:159-61.

2. Kondro W. Canadian scientists urge government to develop antibiotic plan. Lancet. 2002:360:1230.

3. Gallois M, Rothkötter H, Bailey M, Stokes C, Oswald I. Natural alternatives to in-feed antibiotics in pig production: can immunomodulators play a role? Animal. 2009;3:1644-61.

4. Mateo CD, Peters DN, Stein HH. Nucleotides in sow colostrum and milk at different stages of lactation. J Anim Sci. 2004;82:1339-42.

5. Domeneghini C, Di Giancamillo A, Arrighi S, Bosi G. Gut-trophic feed additives and their effects upon the gut structure and intestinal metabolism. State of the art in the pig, and perspectives towards humans. Histol Histopathol. 2006:21:273-83

6. Cosgrove M. Nucleotides. Nutrition. 1998;14:748-51.

7. Mateo $\mathrm{CD}$, Stein $\mathrm{HH}$. Nucleotides and young animal health: can we enhance intestinal tract development and immune function? In: Lyons TP, Jacques KA, editors. Nutritional Biotechnology in the Feed and Food Industries. Nottingham: Nottingham University Press; 2004. p. 159-70.

8. Pluske JR, Hampson DJ, Williams IH. Factors influencing the structure and function of the small intestine in the weaned pig: a review. Livest Prod Sci. 1997;51:215-36.

9. Li J, Xing J, Li D, Wang X, Zhao L, Lv S, et al. Effects of $\beta$-glucan extracted from Saccharomyces cerevisiae on humoral and cellular immunity in weaned piglets. Arch Anim Nutr. 2005:59:303-12.

10. Li J, Li D, King J, Cheng Z, Lai C. Effects of fi-glucan extracted from Saccharomyces cerevisiae on growth performance, and immunological and somatotropic responses of pigs challenged with Escherichia coli lipopolysaccharide1. J Anim Sci. 2006;84:2374-81.

11. Davis M, Maxwell C, Erf G, Brown D, Wistuba T. Dietary supplementation with phosphorylated mannans improves growth response and modulates immune function of weanling pigs. J Anim Sci. 2004;82:1882-91.

12. Kiarie EG, Nyachoti CM, Slominski BA, Blank G. Growth performance, gastrointestinal microbial activity, and nutrient digestibility in early-weaned pigs fed diets containing flaxseed and carbohydrase enzyme. J Anim Sci. 2007:85:2982-93

13. Masey-O'Neill H, Singh M, Cowieson A. Effects of exogenous xylanase on performance, nutrient digestibility, volatile fatty acid production and digestive tract thermal profiles of broilers fed on wheat-or maize-based diet. Br Poult Sci. 2014;55:351-9.

14. Kiarie EG, Slominski BA, Krause DO, Nyachoti CM. Nonstarch polysaccharide hydrolysis products of soybean and canola meal protect against enterotoxigenic Escherichia coli in piglets. J Nutr. 2008;138:502-8.

15. Sauer N, Mosenthin R, Bauer E. The role of dietary nucleotides in singlestomached animals. Nutr Res Rev. 2011;24:46-59.

16. Canadian Council on Animal Care. CCAC guidelines on: the care and use of farm animals in research, teaching and testing. Ottawa: Canadian Council on Animal Care; 2009.

17. Rakhshandeh A, de Lange CFM. Evaluation of chronic immune system stimulation models in growing pigs. Animal. 2012;6:305-10.

18. NRC. Nutrient Requirements of Swine. 11th ed. Washington, D.C.: National Academic Press; 2012.

19. AOAC. Official methods of analysis of the AOAC. 15th ed. Washington, D.C.: Association of Official Analytical Chemists; 1990.
20. Sauer N, Eklund M, Roth S, Rink F, Jezierny D, Bauer E, et al. Short-term effect of dietary yeast nucleotide supplementation on small intestinal enzyme activities, bacterial populations and metabolites and ileal nutrient digestibilities in newly weaned pigs. J Anim Physiol Anim Nutr. 2012;96:700-8.

21. Andres-Elias N, Pujols J, Badiola I, Torrallardona D. Effect of nucleotides and carob pulp on gut health and performance of weanling piglets. Livest Sci. 2007;108:280-3.

22. Liu YL, Li DF, Gong LM, Yi GF, Gaines AM, Carroll JA. Effects of fish oil supplementation on the performance and the immunological, adrenal, and somatotropic responses of weaned pigs after an lipopolysaccharide challenge. J Anim Sci. 2003:81:2758-65.

23. Liu Y, Huang J, Hou Y, Zhu H, Zhao S, Ding B, et al. Dietary arginine supplementation alleviates intestinal mucosal disruption induced by Escherichia coli lipopolysaccharide in weaned pigs. Br J Nutr. 2008;100:552-60.

24. Weber TE, Schinckel AP, Houseknecht KL, Richert BT. Evaluation of conjugated linoleic acid and dietary antibiotics as growth promotants in weanling pigs. J Anim Sci. 2001;79:2542-9.

25. Skinner LD, Levesque CL, Wey D, Rudar M, Zhu J, Hooda S, et al. Impact of nursery feeding program on subsequent growth performance, carcass quality, meat quality, and physical and chemical body composition of growing-finishing pigs. J Anim Sci. 2014;92:1044-54.

26. Wu S, Zhang F, Huang Z, Liu H, Xie C, Zhang J, et al. Effects of the antimicrobial peptide cecropin AD on performance and intestinal health in weaned piglets challenged with Escherichia coli. Peptides. 2012:35:225-30.

27. Niewold TA. The nonantibiotic anti-Inflammatory effect of antimicrobial growth promoters, the real mode of action? A hypothesis. Poult Sci. 2007: 86:605-9.

28. Bode C, Diedrich B, Muenster S, Hentschel V, Weisheit C, Rommelsheim K, et al. Antibiotics regulate the immune response in both presence and absence of lipopolysaccharide through modulation of Toll-like receptors, cytokine production and phagocytosis in vitro. Int Immunopharmacol. 2014;18:27-34.

29. Louis JA, Lambert PH. Lipopolysaccharides: from immunostimulation to autoimmunity. Springer Semin Immunopathol. 1979;2:215-28.

30. Yeaman MR. Platelets: at the nexus of antimicrobial defence. Nat Rev Microbiol. 2014;12:426-37.

31. Hou Y, Wang L, Ding B, Liu Y, Zhu H, Liu J, et al. Dietary a-ketoglutarate supplementation ameliorates intestinal injury in lipopolysaccharidechallenged piglets. Amino Acids. 2010:39:555-64.

32. Hampson DJ. Alterations in piglet small intestinal structure at weaning. Res Vet Sci. 1986:40:32-40.

33. Uauy R, Quan R, Gil A. Role of nucleotides in intestinal development and repair: implications for infant nutrition. J Nutr. 1994;124:1436S-41S.

34. Grimble GK. Why are dietary nucleotides essential nutrients? Br J Nutr. 1996; 76:475-8.

35. Spring P, Wenk C, Dawson K, Newman K. The effects of dietary mannaoligosaccharides on cecal parameters and the concentrations of enteric bacteria in the ceca of salmonella-challenged broiler chicks. Poult Sci. 2000;79:205-11.

36. Kluger MJ. Fever: role of pyrogens and cryogens. Physiol Rev. 1991;71:93-127.

37. Pi D, Liu Y, Shi H, Li S, Odle J, Lin X, et al. Dietary supplementation of aspartate enhances intestinal integrity and energy status in weanling piglets after lipopolysaccharide challenge. J Nutr Biochem. 2014;25:456-62.

38. Lomax LG. Porcine proliferative enteritis-characterization of the naturally occurring and experimental disease. PhD Thesis. United States of America: lowa State University; 1981

39. Wannemacher RW. Key role of various individual amino acids in host response to infection. Am J Clin Nutr. 1977;30:1269-80

40. Johnson RW. Inhibition of growth by pro-inflammatory cytokines: an integrated view. J Anim Sci. 1997;75:1244-55.

41. Webel DM, Finck BN, Baker DH, Johnson RW. Time course of increased plasma cytokines, cortisol, and urea nitrogen in pigs following intraperitoneal injection of lipopolysaccharide. J Anim Sci. 1997;75:1514-20.

42. Owusu-Asiedu A, Nyachoti CM, Marquardt RR. Response of early-weaned pigs to an enterotoxigenic (K88) challenge when fed diets containing spray-dried porcine plasma or pea protein isolate plus egg yolk antibody, zinc oxide, fumaric acid, or antibiotic. J Anim Sci. 2003;81:1790-8.

43. Gaskins H, Collier C, Anderson D. Antibiotics as growth promotants: mode of action. Anim Biotechnol. 2002;13:29-42.

44. Kogan $\mathrm{G}$, Kocher A. Role of yeast cell wall polysaccharides in pig nutrition and health protection. Livest Sci. 2007;109:161-5. 